\title{
Avaliação em saúde e os caminhos institucionais
}

\section{Health evaluation and the institutional ways}

Em dezembro de 1995 o Instituto Materno Infantil de Pernambuco (IMIP) publicava a Edição Especial da então "Revista do IMIP", intitulada "AVALIAÇÃO NA ASSISTÊNCIA MATERNO-INFANTIL". Fruto de um esforço organizacional, apoiado pela Cooperação Internacional (Banco Interamericano para o DesenvolvimentoBID), para promover a implementação e avaliação de seus programas e serviços, demarcava naquele momento a gestação de um grupo de estudos em Avaliação e Saúde que teria como objetivo ser um catalizador das diversas ações direcionadas ao aprimoramento da qualidade dos serviços prestados, a partir das análises setoriais, mas que também pudesse contribuir com a missão institucional de favorecer o debate e o aprimoramento do sistema de saúde, por intermédio de seus diversos instrumentos e estratégias.

Seu periódico científico, um desses instrumentos, evoluiu. Transformou-se, seis anos mais tarde, nesta conceituada "Revista Brasileira de Saúde Materno Infantil" que, em seu quinto ano de existência como sucedânea da "Revista do IMIP", comemora, também, o desenvolvimento do então "Núcleo de Pesquisas", este, igualmente há cinco anos, transformado na atual "Diretoria de Pesquisas" do IMIP, abrigando os grupos credenciados ao CNPq - "Saúde da Criança", Saúde da Mulher", "Alimentação e Nutrição", "Violência" e a já consolidada linha de "Avaliação em Saúde" .

Este último nasceu e cresceu atento a percorrer caminhos que oferecessem possibilidades de desenvolvimento da capacidade de avaliação interna, contribuindo igualmente com a produção científica institucional, sem esquecer, entretanto, da fundamental e necessária articulação interinstitucional e internacional que propiciasse seu aprimoramento técnico na mesma medida em que favorecia o aprimoramento do Sistema Único de Saúde.

É neste cenário que o hoje Instituto Materno Infantil Prof. Fernando Figueira (IMIP), por intermédio de seu periódico, agora trimestral, acolhe a iniciativa do Grupo de Estudos de Avaliação em Saúde (GEAS/IMIP) ao coordenar a publicação desta Edição Especial temática, celebrando uma década de conquistas institucionais e avanços em parceria neste campo do conhecimento. Coerente com seu novo papel de periódico referenciado por diversas bases de indexação científica, a Revista Brasileira de Saúde Materno Infantil proporciona, desta feita, um espaço para a apresentação de diversas experiências na área, fruto do pensamento e do estudo de pesquisadores com inserção nacional e local - atentos ao cumprimento de sua missão - mas, também, favorecendo o intercâmbio de teorias e perspectivas enriquecidas pela opinião e contribuição de pesquisadores internacionais, estabelecendo assim mais um marco na trajetória que, olhando para o futuro, resgata sua história ao evocar a indispensável participação nos movimentos que constroem a Avaliação em Saúde no Brasil.

Isabella Samico

Instituto Materno Infantil Professor Fernando Figueira. Recife, PE, Brasil.

Zulmira Maria de Araújo Hartz

Departamento de Epidemiologia e Métodos Quantitativos em Saúde. Escola Nacional de Saúde Pública. Fundação Oswaldo Cruz. Rio de Janeiro, RJ, Brazil. 